\title{
Possible Therapeutic Effects of Ozone Mixture on Hypoxia in Tumor Development
}

\author{
MARGHERITA LUONGO, ANNA LISA BRIGIDA, LUIGI MASCOLO and GENNARO GAUDINO
}

\author{
Department of Anesthesiological, Surgical and Emergency Sciences, University of Campania, Naples, Italy
}

\begin{abstract}
Recent literature highlights that ozone therapy could be considered a viable adjuvant therapy in oncological patients receiving radio-chemotherapy. The use of ozone therapy in these patients enhances the action of chemotherapy and at the same time reduces side-effects, such as nausea, vomiting, opportunistic infections, buccal ulcers, hair loss and fatigue. Such positive therapeutic effects of ozone therapy can cause a larger physical and mental wellbeing resulting in improved quality of life. This work reviews the recent acquisition of scientific knowledge regarding the ozone therapy and highlights the molecular and cellular pathways involved.
\end{abstract}

\section{Hypoxia and Cancer}

Hypoxia plays critical roles in the pathobiology of heart diseases, including myocardial ischemia. Hypoxia is also associated with cancer, stroke, and chronic lung disease, which are responsible for $60 \%$ of deaths in the United States (1). Humans have evolved complex circulatory, respiratory and neuroendocrine systems to ensure that oxygen levels are precisely maintained, since an excess or a deficiency may result in the death of cells, tissue or the organism (2). Oxygen homeostasis is at the basis of evolution, development and physiology of the tumoral disease. Indeed, all the nucleated cells perceive and respond to hypoxia. In condition of reduced oxygen availability, hypoxia-inducing factor 1A $(H I F 1 A)$ protein regulates the transcription of genes that mediate the adaptive response (3-4) to hypoxic stress (3-5). However, in hypoxic conditions, HIF1A presence may also indirectly decrease mRNA expression by regulating transcriptional repressors and microRNA genes (3-5). HIF IA has been identified in human cells as regulator

Correspondence to: Margherita Luongo, Via Capomazza 11, 80078, Possuoli, NA, Italy. Tel: +39 0815263075, e-mail: margluon@gmail.com

Key Words: Ozone, HIF, hypoxia, tumor, review. of erythropoitein, a hormone that controls the production of red blood cells, vascular endothelium growth factor (VEGF) that promotes angiogenesis and glycolytic enzymes that adapt cellular metabolism to hypoxic conditions.

HIF1A is composed by the $\beta$ subunit, constitutively expressed and by the oxygen-regulated subunit (6). In aerobic conditions, as in well-oxygenated cells, HIF1A is hydroxylated by the protein prolyl hydroxylase-domain 2 (PHD2), that uses oxygen and $\alpha$-ketoglutarate as substrates and contains FeII in its catalytic center (7-8). The addition of ahydroxyl group on a proline residue (Pro-OH) of HIF1A facilitates its binding to the Von Hipper-Lindau (VHL) protein, which recruits the ubiquitin, ligase E3. The polyubiquitination of HIF1A flags the protein for degradation by the $26 \mathrm{~S}$ proteasome. The HIF-1 inhibition factor (FIH-1) also uses oxygen to add an -OH group on a residue of asparagine (Asn-OH); HIF1A containing Asn-OH cannot interact with the co-activator protein $\mathrm{p} 300$, thus preventing HIF1A to transcriptionally activate several of its downstream genes (9-10). In hypoxic conditions, Pro and Ans hydroxylations are inhibited and HIF1A rapidly accumulates, dimerizes with HIF1B, recruits p300 and activates the transcription of hundred gene targets by RNA polymerase II (pol II), such as: erythropoietin (EPO), an hormone that stimulates the production of red blood cells; VEGF, which is an angiogenic stimulating factor in the formation of blood vessels; pyruvate dehydrogenase kinase 1 (PDK1), which inhibits the conversion of pyruvate into acetyl-coenzyme A for the oxidation in the mitochondrion. Hypoxic responses can also be mediated by endothelial PAS domain protein 1 (EPAS1), also known with the protein total name of HIF2, a heterodimer composed by aryl hydrocarbon receptor nuclear translocator (ARNT), also known as HIF-1 $\beta$, and EPAS1 (HIF2) itself (analogue of HIF-1A which is also regulated by oxygen-dependent hydroxylation) (11). HIF-1A is present in all the nucleated cells of all metazoica species, while the expression of EPAS1 is limited to certain cell types in among the vertebrate species and it plays an important role in both erythropoiesis and vascularization. 
In cancer development, the presence of a less active form of superoxide dismutase (SOD) dictates an increase of free radicals and reactive oxygen species (ROS) in the cytosol, that causes mithochondrial damage, hyper-fluidity of membranes (lipoperoxidation of the phospholipids), inefficiency and loss of the enzyme functions as electron carriers. The consequences of these mitochondrial damages are the reduction of oxidative phosphorylation and of cellular respiration. This results to a hypoxic condition, which in turn drives the cancer cell towards an anaerobic glycolytic metabolism. It is an altered carbohydrate metabolism, given by increased glycolysis not followed by Krebs cycle and by the oxidative phosphorylation, resulting in low energy efficiency, and characterized by an excessive use of glucose, satisfied by increased gluconeogenesis with the depletion of precursors such as amino acids and fatty acids (12). In this way, the tumor cells are characterized by accumulation of acid lactic and cellular acidosis, energy dissipation (two molecules of ATP from glycolysis versus the thirty-eight molecules of the physiological glycolytic metabolism followed by the Krebs cycle) and finally, increased demand of the glucose precursors (gluconeogenesis) with depletion of the tissue reserves.The hypoxic condition and lactic acidosis determine the activation of the Kirsten ras oncogene homolog KRAS (13) with increased transcription of HIF IA that in turns, induces transcription of several downstream genes encoding glycolytic enzymes, such as hexokinase, aldolase, phosphofructokinase and lactic dehydrogenase (14). In cancer cells under hypoxic conditions, these HIF1A-induced glycolytic enzymes drive an acceleration of the glycolytic flux and rewires glycolysis to lactic fermentation (14).

\section{Regulation of Physiological Cellular Metabolism by HIF}

Even the simple roundworm Caenorhabditis elegans, which consists of approximately 1000 cells and contains no specialized systems for the oxygen delivery, expresses $H I F 1 A$, indicating the primordial function of $H I F 1 A$, to mediate the adaptive responses which allow cells to survive in conditions of oxygen deprivation (1). One way in which HIF IA may promote cell survival under hypoxic conditions is by regulating a signaling switch from oxidative to glycolytic metabolism. The glycolytic enzymes convert glucose into pyruvate, which can be converted either into acetyl-coenzyme A (CoA) for the cycle oxidation in the tricarboxylic acid, or into lactose as a glycolytic end product. HIF $1 A$ activates the expression of lactate dehydrogenase A and PDK1, thus shifting the balance from oxidative to glycolytic metabolism $(15,16)$.

In well-oxygenated cells, pyruvate dehydrogenase (PHD) converts the pyruvate into acetyl-coenzyme A that oxidizes in the tricarboxylic acid cycle (TCA), generating electrons that are transferred through a series of protein complexes
(Electron Transport Chain - ETC) to oxygen and produce water. The proton gradient determined by the ETC is used to synthesize ATP. Under hypoxic conditions, PDK1 inactivates the PDH and the lactate dehydrogenase A (LDHA), and converts the pyruvate into lactate. The glycolytic enzymes expression is also driven under hypoxic conditions to increase the flow during the anaerobic path (1).

As compared with glycolysis, oxidative metabolism yields 18 fold as much ATP per mole of glucose consumed. In aerobic conditions, the electrons are transferred from NADH and flavinadeninadinucleotide (FADH2) (generated by oxidation of acetyl-coenzyme A) to mitochondrial complexI or II and finally, they react with oxygen forming water. In hypoxic conditions, the electron release is increased before the transfer to complex IV, leading to the formation of superoxide, which is then converted into hydrogen peroxide and other toxic reactive oxygen species with a loss of redox homeostasis (17).

\section{HIF1A and Induction of Angiogenesis}

Angiogenesis is a critical step in tumor growth. Hypoxic stress determines the HIF1A activation, which causes the transcription of several angiogenic factors, thus creating an imbalance among stimulating angiogenesis factors and inhibitor factors with abnormal proliferation of endothelial cells and organization in the neo-formed vessels. In young and healthy mice, the legature of the femoral artery brings to the local induction of HIF1A, followed by the transcriptional activation of genes which encode the proangiogenic factor VEGF and other angiogenic factors within the angiogenic limb; after several weeks the normal perfusion is re-established (18). This adaptive vascular response is altered by aging and diabetes, which constitute the main risk factors for the coronary and the peripheral arterial disease (19-23).

VEGF and other secreted factors activate the vascular cells to promote angiogenesis (sprouting of new capillaries from existing vessels) (24). The angiogenic factors can reach the circulation and stimulate the mobilization of angiogenic cells derived from bone marrow (BMDAC), which they partecipate to the angiogenesis (22).

\section{Co-opted Adaptation to Hypoxia in Cancer}

In cancer, co-optation of the physiological cellular responseto hypoxia plays a major role in the disease progression and therapeutic efforts are directed toward the inhibition of HIF1A. Folkman showed the fundamental role of angiogenesis in the primary tumor growth and their metastases (25). The tumor vessels are structurally and functionally abnormal and even highly vascularized cancers may contain area of severe hypoxia. Malignant tumors are characterized by regions of low concentration of $\mathrm{O}_{2}$, often 
associated to radio- and chemotherapy resistance. Hypoxia contributes to the tumor progression through the activation of an adaptive response, mainly by HIF1A and EPAS1 mediated regulation of trasncription. In breast cancer, the $\mathrm{PO}_{2}$ average is $10 \mathrm{~mm} \mathrm{Hg}$ (compared to $>60 \mathrm{~mm} \mathrm{Hg}$ in normal breast tissue) and in primary tumors a $\mathrm{PO}_{2}$ lower than $10 \mathrm{~mm} \mathrm{Hg}$ is associated with a higher risk of metastasis and death (26). In primary tumors, the overexpression of HIFIA and EPASI is associated with a more aggressive phenotype and to an increased mortality (27). HIF1A coordinates the tumor's response to hypoxia by activating transcription of genes that play a fundamental role in angiogenesis (28), genome instability (29), immune evasion (30), metabolic reprogramming (glycolysis) (31), invasion and metastasis (32) and in the radiation-chemotherapy resistance (33). Indeed, HIF1A is able to regulate hundreds of target genes in a particular cancer, such as $N F-k B, C R E B, T P 53, S P / 1$. HIF1A is implicated in the uncontrolled tumor growth (34), stimulating oncogenes such as $c-M Y C$ and $N E M O$, blocking cell death by TP53 inhibition and arresting cell cycle (inhibiting c-MYC) with the production of undifferentiated cells (35). HIF1A is involved in the metabolic switch from oxidative phosphorylation to glycolysis, with consequent reduction of the cellular respiration and increased production of lactic acid. Indeed, HIF1A induces the transcription of genes involved in the glycolytic metabolism, with increased glucose transporter production, glycolytic enzymes, as well as pyruvate and lactate dehydrogenase (36), while it represses genes involved in the mitochondrial respiration (37). Furthermore, angiogenesis is a crucial step for tumor progression to ensure a blood supply supplement that allows aberrant proliferation and tumor expansion. HIF1A has a key role here as well, especially through the activation of the proangiogenesis genes, like VEGF (38). The tetrathiomolydate of ammonium, used in the metabolic kidney disorders, can inhibit HIF1A in cancer cells, especially in ovarian and endometrial cancer, proving capable of limiting tumor angiogenesis (39). Angiogenesis is an essential requirement for the vascular dissemination of tumor.

Several studies show that invasiveness and metastasis are critical steps in malignant solid tumors andare controlled by HIF1A-mediated increase of E-cadherin levels through the up-regulation of transcriptional repressors, such as Snail and SIP1 and in parallel through the over-production of chemokines and pro-invasive proteins of the extracellular matrix (40). Even the resistance to radio- and chemotherapy seems to be regulated by HIF1A, as a study demontrated that ovarian cancer cell lines sensitive to cisplatin show a downregulation of HIF1A levels (41).

The intra-tumoral hypoxia is an important mechanism by which HIF1A is activated in human cancers, but HIF1A is also activated in consequence of loss of functionality of tumor suppressor genes or to an increase in oncogenic functionality (27). Unlike people with Chuvash polycythemia, homozygous for a sense mutation of VHL that partially changes its ability to trigger the ubiquitination of HIF1A, most people with VHL syndrome (type $1,2^{\circ}$ or $2 \mathrm{~B}$ ) are heterozygous for a mutation that leads the loss of functionality (42). The somatic mutation or epigenetic inactivation of other alleles blocks the ubiquitination and degradation of HIF1A. These patients are at high risk of cancers (in particular renal cell carcinoma and the cerebellar hemangioblastoma), which are highly vascularized because of high levels of VEGF and others angiogenic factors regulated by HIF1A (43). A recent study has shown that the bioengeneered production of the VHL could lead to a drastic angiogenesis inhibition and to a significant regression of renal cell carcinoma (44). The METOXIA project (Metastatic tumours facilitated by hypoxic tumour micro-environments), financed by the European Union (EU), aims to study the molecular mechanisms at the basis of tumor hypoxia that regulate the ability to migrate to other part of the body and to survive in unfavourable conditions, and that can adversely affect the outcome of chemotherapy and radiotherapy. The METOXIA team has demonstrated that oxygenation changes affect metastasis and the response to therapy; the team is studying the effectiveness of a growing number of chemotherapeutic agents that function as inhibitors of HIF1A through different molecular mechanisms (45). The challenge is to understand the role of HIF1A in a particular tumor, in order to determinate whether it can be therapeutically targeted and if so, how. Drugs, such as topotecan, are administered intermittently at the maximum tolerated dose as cytotoxic agents, but if administered daily at lower doses, they inhibit HIF1A and the downstream pathways, such as the angiogenesis in tumoral xenograft models (46). Several drugs which were previously utilized for the treatment of other diseases different from cancer, including cardiac glycosides (such as digoxin), have shown to inhibit HIF1A activity and to arrest tumor growth in mice, but it is still not known whether this fact will take place over the dose range tolerated by humans (47). Other blocking agents of HIF1A which are being studied in clinical trials on cancer treatment (histone deacetylase inhibitors, heat shock proteins, and mammalian target of rapamycin (mTOR) inhibit the activity of many other proteins; the extent to which HIF1A inhibition contributes to the therapeutic efficacy is unknown, but it can vary significantly from patient to patient.

\section{Therapeutic Role of Hyperbaric- and Ozone-induced Hyperoxia in Tumors}

Therapies such as hyperbaric oxygen and ozone therapy, that are traditionally utilized in diseases that evolved into ischemia and hypoxia, are being studied as adjuvant treatment in solid tumors. 
These medical gases determine an hyperoxia state that should have an inhibitory effect on malignant tumor, whose critical marker is hypoxia, which is at the bases of cell proliferation mechanisms, angiogenesis, glycolytic metabolism and metastasis. The hyperbaric therapy consists in the administration of $100 \%$ of oxygen at a higher pressure than that atmospheric, thereby leading to an increase of the dissolved oxygen in the plasma and to the transfer of $\mathrm{O}_{2}$ to the tissues in a way independent of hemoglobin (48). As in normal tissues, the $\mathrm{pO}_{2}$ in tumor tissue increases significantly during exposure to the hyperbaric oxygen ( $\mathrm{HBO}$ ) treatment (49); indeed, HBO is always used in diseases characterized by hypoxia and ischemia, since it stimulates angiogenesis, the fibroblast activation with collagen deposition, and epithelialization; on the basis of these actions, HBO should promote the cancers growth.Instead, paradoxically, not only it does not promote tumor growth but the use of HBO in cancer patients may have different therapeutic effects.

\section{Therapeutical Effects of HBO}

HBO shows several therapeutics effects. Indeed it is able to induce the apoptosis of cancer cells by activating the proapoptotic mitogen-activated protein kinase (MAPK) oncogene and the down-regulation of the anti-apoptotic extracellular signal-regulated kinase (ERK1-2) genes (50). HBO reduces cell proliferation through inhibition of cell division (37) and damages cancer cells causing cell death due to the high levels of ROS, through mechanisms induced by hyperoxia and the inefficient anti-oxidant mechanisms of cancer (51). Through an inhibitory action on HIF1A, it shows an anti-angiogenic effect for, that is the key driver of tumor development and metastasis (52). In addition, HBO is able to iduce a phenotype with less invasive and metastatic capacity (53); the metastasis is a complex process that includes the local invasion of cancer cells, the entry into the blood and lymph vessels and the colonization in distant sites. Indeed, angiogenesis is a key factor for the metastasis (54). The HBO-mediated reduced resistance to chemotherapy is due by two mechanisms: 1) it increases tumor perfusion thanks to the development of a physiological vascular network, that allows the chemotherapy to reach the hypoxic center of the tumor; 2) it increases cancer cells sensitivity to chemotherapy (55). Finally, HBO reduces resistant to radiation theraphy by stimulating cell sensitivity, as well as the effective doses of radiation and chemotherapeutic drug and their side effects (56).

Therapeutic hyperoxia can even be achieved with the administration of therapeutical ozone $\left(\mathrm{O}_{3}\right)$. Ozone, compared to $\mathrm{HBO}$ has an easier administration, slow operating costs, fewer side effects and importantly, greater therapeutic effect, mainly due to better hemorheological action and the action on the intestinal mucosa due to rectal insuflation.

\section{Ozone: Chemistry and its Action Mechanisms in Biological Systems}

Ozone $\left(\mathrm{O}_{3}\right)$ is an unstable molecule composed by three oxygen atoms, in cyclic structure, with a strong oxidizing power and capable of enhancing the endogenous anti-oxidant systems. It is ten fold more soluble in water than oxygen.

The typical medical ozone generator uses a pure oxygen stream subjected to a different voltage between 5000 and 15000 Volts. This energy causes the breaking of single molecules of $\mathrm{O}_{2}$ into two unbound oxygen atoms which then recombine with an $\mathrm{O}_{2}$ molecule giving origin to the $\mathrm{O}_{3}$ molecule. The so generated ozone is then mixed with $\mathrm{O}_{2}$ to achieve the desired $\mathrm{O}_{2}-\mathrm{O}_{3}$ mixture. Once produced by the generator, the $\mathrm{O}_{2}-\mathrm{O}_{3}$ mixture is moved towards a two outputs valve. An output is accessible to the operator for withdraw the mixture with a syringe and the other one is directed towards a catalytic destroyer of $\mathrm{O}_{3}$ (made from palladium, nickel and manganese oxides), which has the function to destroy the ozone in surplus, not utilized for the mixture. This is used to prevent that such gas is released in the environment where it can exerce toxic effects, being strongly irritating to inhaled with consequences that can be, at high concentration, even lethal in a few minutes. For this reason, in the medical mixtures, the $\mathrm{O}_{3}$ must be present in very limited concentrations, not higher than $40 \mu \mathrm{g} / \mathrm{ml}$ of $\mathrm{O}_{2}$. Furthermore, it is very important that the oxygen flow entering into the generator has a purity close to $100 \%$. Indeed, the air we breath contains nitrogen to $78 \%$. Therefore, in the generator, in atomic oxygen presence, nitrogen oxides, highly toxic and and then not available for medical purpose, could be produced. The obtained gas can not be stored and must be immediatly used after removal from the generator. The optimum ozone dose, able to provide an anti-infiammatory and analgesic effect, in absence of adverse reactions, has been estimated between 20 and 40 $\mu \mathrm{g} / \mathrm{ml}$ of gas per $\mathrm{ml}$ of blood. The tolerance range is instead much wider: 10-80 $\mu \mathrm{g} / \mathrm{ml}$. Above $40 \mu \mathrm{g} / \mathrm{ml}$ ozone has an antimicrobial and antiviral effect, dose-dependent, as evidenced by several studies. In one of these studies, the activity of oxygen-ozone mixture was evaluated in vitro, on the growth of some Pseudomonas Aeruginosa and Staphylococcus aureus strains. In the second study, the hepatic function in patients with virus $\mathrm{B}$ and $\mathrm{C}$ after ozone treatment has been evaluated (57).

Ozone is soluble in the liquid according to Henry's law, that is a valid law for the gases that do not react with the solvent $(\mathrm{P}=\mathrm{KC}$, where $\mathrm{P}$ is the gas pressure on the solution, $\mathrm{K}$ is a constant related to the gas and temperature, $\mathrm{C}$ is the gas concentration) (58). Considering the water as solvent, the ozone does not react with the solvent and gives rise to a stable solution for about $48 \mathrm{~h}$, and it is commonly used as disinfectant. Otherwise, if the ozone is dissolved in biological liquids, such as plasma, lymph, urine, it reacts immediately, according to the following scheme:

$\mathrm{O}_{3}+$ biomolecules $\rightarrow \mathrm{O}_{2}+\mathrm{O}$. 
In biological systems, the oxygen in the atomic state $(\mathrm{O})$ is highly reactive and reacts with fat polyunsaturated acids (PUFAs), uric acid, thiols, cysteine-rich proteins, antioxidants such as ascorbic acid, reduced glutathione (GSH), albumin etc. A small part of ozone dose dissolved in the plasma is instantly inactivated by free anti-oxidants (such as uric acid, ascorbic acid and albumin) and the remaining concentration reacts with PUFAs. All these compounds are obviously electron donors (reducing agents) and thereafter undergo oxidation. Particularly, ozone in lipophilic environment, reacts with compounds containing double bonds $(-\mathrm{C}=\mathrm{C}$ - present in unsaturated fat acids), giving rise to an additional compound called ozonide. In this ozonolysis reaction, the double bond opens adding the three atoms of oxygen and like a final reaction it will give rise, besides the peroxide hydrogen (reactive oxygen species) also to lipid oxidation products (lipid oxygenated products -LOPs), that stimulate the production of anti-oxidant enzymes, such as superoxide dismutase (SOD), glutathione peroxidase(GSH$\mathrm{Px}$ ), catalase (CAT), glucose 6-phoshate dehydrogenase $(\mathrm{G} 6 \mathrm{PDH})$ and stimulate stress proteins, such as the hemeoxygenase (HMOX) (59). It has been suggested that LOPs are able, at the bone marrow level, to activate the metalloproteinase release. In particular, among these enzymes, the metalloprotease 9 (MMP9) is able to release stem cells into the bloodstream and their subsequent localization in damaged areas, in ischemic and infarcted tissues, resulting in damage limitation and better chance of healing (60).

In biological fluids of hydrophilic environment, these LOPs compounds (derived from the reaction between ozone and carbon double bonds- containing molecules) are rapidly converted in stable hydroperoxides. Subsequently, changes in $\mathrm{pH}$ destabilize the hydroperoxides, causing the break of the molecule, producing compounds of lower length and releasing hydrogen peroxide $\left(\mathrm{H}_{2} \mathrm{O}_{2}\right)$ and aldehydes (in particular 4-hydroxynonenal (4-HNE), a reactive aldehyde produced in relatively large quantities during the lipid peroxidation). The presence of aldehydes have a protective action against the toxic components. Aldehydes, conveyed by the albumin, determinate oxidative stress in all body tissues: liver, endocrine glands, central nervous system, etc. It has been demonstrated that $4-\mathrm{HNE}$, at certain levels $(0.1-$ $0.7 \mu \mathrm{M})$, appears to act as a protective agent for itself and for other toxic components. At picomolar levels, 4-HNE activates several signal molecules, such as $\gamma$-glutamate cysteine ligase, heat shock protein-70 (HSP-70) and hemeoxygenase-I, an enzyme involved in glucose control and prevention of myocardial ischemia (61); in addiction, 4-HNE activates some anti-oxidant enzymes: superoxide dismutase, GSH-Px, CAT, G6PDH (62).

It is important to note that in the presence of $\mathrm{Fe}^{++}$the decomposition of hydrogen peroxide is catalized with formation of reactive oxygen radicals, such as the hydroxyl radical ${ }^{\circ} \mathrm{OH}$ according to the following scheme (63):

$$
\mathrm{Fe}^{++}+\mathrm{H}_{2} \mathrm{O}_{2} \rightarrow \mathrm{Fe}^{+++}+\mathrm{OH}^{\bullet}+\mathrm{OH}^{-} \text {. }
$$

The oxygen-reactive species that are formed have an extremely low half-life and can result to some relevant cell damages. Particular attention should be placed to avoid the formation of an excess of reaction products with ozone as it is possible the formation of toxic compounds, such as peroxynitrite $\left(\mathrm{OR}=\mathrm{NOO}^{-}\right)$and anion hypochlorite $\left(\mathrm{CIO}^{-}\right)$ (64). The decomposition of the hydrogen peroxidate produced by the ozone reaction, through several biochemical modifications, it seems to indirectly favour a greater intake of oxygen at the tissue level. In this contest it is considered that the hydrogen peroxide formed as a result of the ozone reaction with biochemical molecules, easily spreads from the plasma to the cells (erythrocytes, leukocytes, platelets, lymphocytes and endothelial cells), in which cytoplasm, according to the type of cell, undertake activities to stimulate the various metabolic pathways, resulting in numerous biochemical effects (62). It is interesting to consider that the concentration of $\mathrm{H}_{2} \mathrm{O}_{2}$ in plasma is about 10 times higher than intracellularly and its rapid reduction to water takes place due to the high concentrations of GSH, CAT and GSH-Px; however, for the activation of the numerous biochemical pathways it must be present in concentrations above the threshold value (65).

The red cell mass absorbs most of $\mathrm{H}_{2} \mathrm{O}_{2}$ : the oxidation of GSH and the consequent reduction of $\mathrm{H}_{2} \mathrm{O}_{2}$ to water triggers a series of biochemical interactions and the increase of 2,3diphosphoglycerate.

Red cells in a self-regulation process to rebuilt the NADPH level decreased during the oxidative stress by ozonation, activate G6PDH and the pentose pathway, which determine the increase in 2,3 diphosphoglycerate with a rightward shift of the dissociation curve of the oxyhemoglobin, resulting in increases oxygen delivery to ischemic tissues (66).

Peroxidation of erythrocyte membrane determines the relaxation of phospholipid molecules with greater membrane fluidity and consequent increase of erythrocyte deformability and reduction of hemolysis; in addition, this peroxidation gets to an increase of the negative charge of the membrane with a less tendency to stacking, reduction of viscosity and a decrease in the erythrocyte sedimentation rate.

All these events lead to a clear improvement in rheology. Hydrogen peroxide, instead, once penetrated into the cytoplasm of the blood mononuclear cells (lymphocytes and monocytes), by oxidizing cysteine, activates a tyrosine kinase, which in turn phosphorylates the transcription nuclear factor $\mathrm{kB} \quad(\mathrm{Nf}-\mathrm{kB})$, responsable for other biochermical events. This cascade of events ends with the activation, by means of the Nf-kB factor, of several genes responsable for the synthesis of receptors and cytokines, 
resulting in the production of IFN- $\gamma$, TNF- $\alpha$, IL- 2 and IL- 6 , which explains the important immunomodulatory action of ozone (66). In endothelial tissue, the response to ozonized plasma is represented by the release of NO with vasodilation and an increased secretion of VEGF with neoformation of vessels (neo-angiogenesis). Topically on wounds, it exerts its action with the production of EGF and FGF that determine the endothelial cell proliferation, (fibroblasts and keratinocytes), jointly to an increased synthesis of the components (fibrin, fibronectin, ialuronic acid) of the interstitial matrix (66).

\section{Pharmacological Action of Oxygen-ozone Mixture}

$\mathrm{O}_{3}$-induced hyperoxia shows several therapeutic actions. One of the most important is the trophic action: by disinfection (not sterilization) and stimulation of granulation tissue and by repair processes through neo-angiogenesis, with marked improvement of local blood microcirculation, greater oxygen contribution and more rapid elimination of toxic waste products (67). Ozone, through the production of ROS, acts as an antimicrobial oxidant in a similar way to what occurs in activated leukocytes during phagocytosis. It is plausible to image that this increase is responsable for the antibacterical effect against anaerobic bacteria, assuming the absence of enzymes, such as superoxide dismutase, capable of neutralizing the oxidizing action of these free radicals. The ozone could act directly through its peroxides $(\mathrm{OH}-)$ by attacking enzymes, DNA, bacterial membrane phospholipids, the capsid of the virus or indirectly stimulating the production of white blood cells, promoting better oxygenation, resulting in a prolongation of leukocytic activity (oxygen killer) and phagocytosis (68). Its antioxidant property triggers activation of enzymes that block peroxides and free radicals, increasing the abundance of detoxifying agents, such as superoxide dismutase, glutathione peroxidase, and catalase (69). Ozone also shows analgesic activity: it can be effective for preventing the development of neuropathic pain, through the modulation of specific proinflammatory or pro-apoptotic caspases in the brain (70). As metabolic characteristic, ozone accelerates the citric acid cycle and stimulates mitochondrial activity (71). Its capacity to increase the production of IFN, IL- 2 and TNF- $\alpha$ gives the immunomodulatory activity (72). Ozone ensures good oxygenation, good perfusion, good oxygen consumption in the periphery, increases the platelet deformability, reduces blood viscosity, prolongs the PT reducing fibrinogen, enables a laminar flow after induced ischemia (73). Experimental data in rats show that damages associated with myocardial ischemia/reperfusion can be counteracted by an acute $\mathrm{O}_{3}$ pretreatment (74). All these events defeat hypoxia and promote the arrival of antibiotics and chemotherapeutics in the hypoxic site of a possible infection or tumor (75).
The first response to tissue injury is always represented by inflammation. Therefore, the preventive ozone administration may influence the onset and/or the course of this pathological condition. In precocious $\mathrm{O}_{3}$-treated patients with sepsis, severe infections and/or critically diseases, it is possible to achieve a reduction of organ damage. The mixture $\mathrm{O}_{2}-\mathrm{O}_{3}$ has a potent in vitro antibacterical activity comparable to the powerful activity of $\mathrm{NO}$, controls the inflammatory processes in vivo and modulates the phagocytic activity which is the first line of defense against bacteria and toxins. So that, the $\mathrm{O}_{2}-\mathrm{O}_{3}$ mixture increases the production/release of pro-inflammatory cytokines in different abdominal organs and it is capable of limiting the occurrence of severe infection; it neutralizes the action of endogenous ROS by stimulating the antioxidant enzymes production (GSH, SOD, CAT) (76).

Antitumoral activity of ozone could be due to hyperoxia. "Does ozone really cure cancer?" Bocci wonders in an article published in 2008 on the International Journal of Cancer (77). In this article, he analyzes the results obtained by Schulz et al., which have implanted tumor cells in 14 rabbits, and the intraperitoneal injection for 5 days of $240 \mathrm{ml}$ of $\mathrm{O}_{2^{-}}$ $\mathrm{O}_{3}$ mixture has cured 6 of 14 rabbits (78). The title of this article is a provocation and the same author explains not fall into simple optimism about the limits of this study, but at the same time, he considers that the results are interesting and he urges the scientific community to explore the underlying mechanisms of ozone therapeutic action in malignat tumors. The tumor hypoxia determines a selection of tumor cells with reduced apoptosis, increases the angiogenic capacity and the increases tumor aggressiveness. Furthermore, it determines the increased resistance to radiotherapy and chemotherapy (79). The return to normoxic state, that is obtained with a $\mathrm{O}_{2}-\mathrm{O}_{3}$ prolonged cycle that corrects the tumoral hypoxia, reduces tumor growth and making it less metastatic (80).

Several studies highlight that the $\mathrm{O}_{2}-\mathrm{O}_{3}$ antitumor mechanisms are conducted by determining several key issues. In a study conduced by the Washington University, researchers showed that the in vitro growth of human cancer cells is selectively inhibited in a dose dependent manner by increasing $\mathrm{O}_{3}$ doses. Its inhibitory action on tumor growth occurs through different action mechanisms (81). In a study conduced by Coppola et al. it is proved the increase of $\mathrm{O}_{2}$ peripheral saturation after auto-emotrasfusion treatment (200 $\mathrm{ml}$ of ozonated blood reinfused) and the increase continues with the repeated treatments (82). Moreover, the correction of the abnormal hemorheological parameters (platelet aggregation, blood viscosity, erythrocyte deformability) could be another key factor (83), togheter with the right shift of hemoglobin saturation curve with an increase of $\mathrm{O}_{2}$ cessation (73). It has been demonstrated that the use of $\mathrm{O}_{2}-\mathrm{O}_{3}$ mixture in patients with peripheral occlusive arterial disease showed 
benefic effects, such as pain and amputations reduction. It has been also demonstrated that in 88 patients with advanced cancers, the auto-emotrasfusion treatment leads to an increase of tumor $\mathrm{pO}_{2}$. In addition, they showed a significant increase in the concentration of hemoglobin and the $\mathrm{O}_{2}$ transfer at the tissue level (79). Hyperoxia $\mathrm{O}_{3}$-mediated inhibits the HIF1A factor, whose level is increased in many tumor biopsies and correlated with the invasiveness and metastatic degree (84). Ozone therapy can improve the anti-tumor immunotherapy activating the anti-tumor $\mathrm{T}$ lymphocytes and natural killer cells (85). Bocci claims that ozone can induce the synthesis of various powerful pro-inflammatory cytokines that would activate macrophages setting off a massive immune reaction (66). Ozone is able to reduce certain infections caused by the immunosuppression present in oncological patients (vaginitis, prostatitis, etc.). In several studies, it has been proven that radio- and chemo-resistence of tumors is regulated by HIF1A. $\mathrm{Ai}$ and Lu have shown that, in ovarian cancer cells, the overexpression of HIF1A is associated to the reduction of apoptosis induced by cisplatin (41). In another recent study, it was shown that, through a mechanism of autophagic protection induced by HIF1A, the lung cancer cells were less susceptible to apoptosis induced by cisplatin (86). Hyperoxia $\mathrm{O}_{3}$-induced, counteracting the HIF1A factor, should increase the chemotherapy effect, by reducing the cancer cell resistance; furthermore, the hemorheological effects should facilitate the chemotherapy arrival at the level of hypoxic tumor nucleus; these two actions would lead to a reduction of effective chemotherapy's doses, and to a consequent reduction of its toxicity and side effects. Indirectly, it counteracts many adverse chemotherapy effects, for example, it is effective against dilated cardiomyopathy induced by doxorubicin (87), reduces the rate of infections increasing the immune system, increases the hemoglobin concentration with reduced sense of fatigue, reduces the incidence nausea and vomiting caused by the chemotherapy.

All these benefic actions make the $\mathrm{O}_{3}$ therapy an extremely valuable adjuvant treatment in cancer pathology, because, reducing the side effects of radiotherapy and chemotherapy, increases the psycophysical wellbeing of cancer patients and improves their quality of life.

\section{Ozone Administration Routes}

The ozone administration takes place through several routes: subcutaneous injection, intramuscular injection, intradiscal, intraarticular, intraforaminal, parental administration (intraperitoneal, intrapleural, intravenous), inflaction endorectal and endo-vaginal. There is also the use of ozonized oils and ointments, very effective for the treatment of infected wounds and ulcer. The subcutaneous and intramuscolar techniques involve the infusion, in divided doses of $60 \mathrm{ml}$ of ozone gas, through a syringe after excluding that the needle is inside the vase. Since the gas mixture in which ozone is dissolved, it is composed for the $95 \%$ by $\mathrm{O}_{2}$, its administration can not be directly intravenous, for the high risk of embolism. Consequently, the systemic approach is represented by the auto-emotransfusion, in which a venous blood volume is previously ozonized with a mixture containing $\mathrm{O}_{3}$ at concentration of $30 \mu \mathrm{g} / \mathrm{ml}$. The process involves the removal of $200 \mathrm{ml}$ of blood, the immediate reinfusion of $20 \mathrm{ml}$ to prevent blood clotting in the connecting pipe. The latter leads the blood from a G19 needle butterfly up to a filter that is connected to a vacuum flask: a glass container, under vacuum, is preferred to the plastic bags, since the latter can be subjected to an erosive action by the ozone. The remaining $180 \mathrm{ml}$ of blood are re-infused with an equal volume of ozonized gas (through a further collector tube to which will be applied the syringe containing the gas), mixed for 3 minutes until achieving a bright red color. The blood once treated, is then slowly reinfused.

Another systemic administration route is the rectal insufflation, that has several advantages compared to the auto-emotransfusion: easy execution, low cost, the absence of any kind of pain, the absence of venous access that is difficult to find in oncological patients. Moreover, it shows additional benefits: being absorbed at the hemorrhoidal plexus level, it determines an oxygenation increase of the portal vein with a consequent improvement of the action of hepatic detoxification, especially in reference to the chemotherapics drugs (88), helps to maintain the oxygenation stable and the $\mathrm{pH}$ of the intestinal mucosa, with a consequent reduction of gastrointestinal side effects due to the chemotherapy drugs (89); at the level of the intestinal mucosa, it blocks the HIF1A factor with an increase of the epithelial barrier of the microbial response, cytokines reduction and of caspases expression, involved in cell death and in the intestinal inflammation (90); to rectal level, it contrasts prostatitis and rectal bleeding in patients with prostate cancer treated with radiotherapy (79). Considering the countless benefits of the rectal insufflation, it could be the preferential administration route in order to use the ozone as a adjuvant therapy in cancer patients receiving chemotherapy. The dosage which may be used is that of $180 \mathrm{ml}$ (three insufflations of $60 \mathrm{ml}$ ) at $90 \mu \mathrm{g} / \mathrm{ml}$ for four times a week.

\section{Use of Ozonated Water in Cancer Patients}

In patients treated with fluorine-uracil and cisplatin, with the occurrence of buccal canker sores, ozonated water could be used. This special water has proved to be widely effective in reducing the occurrence and the size of the tumor. In a recent study conducted on the safety of the ozonated water and of its anti-tumor effects, using a murine model, the local administration of ozonated water was not associated with any 
adverse effects in normal tissues. On the other hand, the local administration of ozonated water directly in the necrosis induced by the tumor tissue has inhibited the proliferation of tumor cells in a dose dependent manner. These results indicate that the ozonated water has not effect on normal tissue, but it only damages the tumor tissue, inducing selectively the necrosis. It is possible that it has an effect through the production of reactive oxygen species. Moreover, the necrosis induction rather than apoptosis is very useful on the purposes of the tumoral immunity. On the basis of these results, the administration of ozonated water is a safe and potentially simple treatment as adjuvant to existing anticancer therapies (91).

\section{Conclusion}

According to scientific evidence, ozone therapy could be considered a viable adjuvant therapy in oncological patients receiving radio-chemotherapy. The use of ozone therapy in these patients enhances the action of chemotherapy and at the same time reduces the side-effects, such as nausea, vomiting, opportunistic infections, buccal ulcers, hair loss and fatigue. Such positive therapeutic ozone effects can cause a larger physical and mental wellbeing resulting in improved quality of life. It is desirable, in the shortest time, the start of clinical trials on humans to verify the safety and efficiency of ozone mixture as adjuvant therapy in cancer patients.

\section{Aknowledgements}

The Authors thank Proffesors Ludovico Coppola, Carlo Luongo, DrsPaolo Angeli, Dario Apuzzo, Maurizio Arena, Andrea Frassinetti, Giovanni Santangelo, Felice Spaccavento, Luisa Spinelli and Pasquale Sommella for their useful assistance.

\section{References}

1 Gregg L and Semenza GL: Oxygen Sensing, Homeostasis, and Disease.N Engl J Med 365: 537-547, 2011.

2 Weir EK, López-Barneo J, Buckler KJ and Archer SL: Acute oxygen-sensing mechanisms. N Engl J Med 353: 2042-2055, 2005.

3 Mole DR, Blancher C, Copley RR, Pollard PJ, Gleadle JM, Ragoussis $\mathbf{J}$ and Ratcliffe PJ: Genome-wide association of hypoxia-inducible factor (HIF)-1alpha and HIF-2alpha DNA binding with expression profiling of hypoxia-inducible transcripts. J Biol Chem 284: 16767-16775, 2009.

4 Xia X, Lemieux ME, Li W, Carroll JS, Brown M, Liu XS and Kung AL: Integrative analysis of HIF binding and transactivation reveals its role in maintaining histone methylation homeostasis. Proc Natl Acad Sci USA 106: 4260-4265, 2009.

5 Manolo DJ, Rowan A, Lavoie T, Natarajan L, Kelly BD, Ye SQ, Garcia JG and Semenza GL:Transcriptional regulation of vascular endothelial cell responses to hypoxia by HIF-1. Blood 105: 659-669, 2005.
6 Wang GL, Jiang BH, Rue EA and Semenza GL: Hypoxiainducible factor 1 is a basic-helix-loop-helix-PAS heterodimer regulated by cellular $\mathrm{O}_{2}$ tension. Proc Natl Acad Sci USA 92: 5510-5514, 1995.

7 Semenza GL: Oxygen homeostasis. Wiley Interdiscip Rev Syst Biol Med 2: 336-361, 2010.

8 Kaelin WG Jr and Ratcliffe PJ:Oxygen sensing by metazoans: the central role of the HIF hydroxylase pathway. Mol Cell 30: 393-402, 2008.

9 Iyer NV, Kotch LE, Agani F, Leung SW, Laughner E, Wenger RH, Gassmann M, Gearhart JD, Lawler AM, Yu AY and Semenza GL: Cellular and developmental control of $\mathrm{O}_{2}$ homeostasis by hypoxia-inducible factor 1 alpha. Genes Dev 12: 149-162, 1998.

10 Ryan HE, Lo J and Johnson RS:HIF-1 alpha is required for solid tumor formation and embryonic vascularization. EMBO J 17: 3005-3015, 1998.

11 Highet AR, Khoda SM, Buckberry S, Leemaqz S, Bianco-Miotto T, Harrington E, Ricciardelli C and Roberts CT: Hypoxia induced HIF-1/HIF-2 activity alters trophoblast transcriptional regulation and promotes invasion. Eur J Cell Biol 94: 589-602, 2015.

12 Otto AM: Warburg effect(s)-a biographical sketch of Otto Warburg and his impacts on tumor metabolism. Cancer Metab 4: 5, 2016.

13 Bousquet MS, Ma JJ, Ratnayake R, Havre PA, Yao J, Dang NH, Paul VJ, Carney TJ, Dang LH and Luesch H: Multidimensional Screening Platform for Simultaneously Targeting Oncogenic KRAS and Hypoxia-Inducible Factors Pathways in Colorectal Cancer. ACS Chem Biol 11: 1322-1331, 2016.

14 Payen VL, BrissonL, Dewhirst MW and Sonveaux P: Common responses of tumors and wounds to hypoxia. Cancer J 21: 7587, 2015.

15 Kim JW, Tchernyshyov I, Semenza GL and Dang CV: HIF-1mediated expression of pyruvate dehydrogenase kinase: a metabolic switch required for cellular adaptation to hypoxia. Cell Metab 3: 177-185, 2006.

16 Papandreou I, Cairns RA, Fontana L, Lim AL and Denko NC: HIF-1 mediates adaptation to hypoxia by actively downregulating mitochondrial oxygen consumption. Cell Metab 3: 187-197, 2006.

17 Hamanaka RB and Chandel NS: Mitochondrial reactive oxygen species regulate hypoxic signaling. Curr Opin Cell Biol 21: 894899, 2009.

18 Bosch-Marce M, Okuyama H, Wesley JB, Sarkar K, Kimura H, Liu YV, Zhang H, Strazza M, Rey S, Savino L, Zhou YF, McDonald KR, Na Y, Vandiver S, Rabi A, Shaked Y, Kerbel R, Lavallee $\mathrm{T}$ and Semenza GL: Effects of aging and hypoxiainducible factor-1 activity on angiogenic cell mobilization and recovery of perfusion after limb ischemia. Circ Res 101: 13101318, 2007.

19 Botusan IR, Sunkari VG, Savu O, Catrina AI, Grünler J, Lindberg S, Pereira T, Ylä-Herttuala S, Poellinger L, Brismar K and Catrina SB:Stabilization of HIF-1alpha is critical to improve wound healing in diabetic mice. Proc Natl AcadSci USA 105: 19426-19431, 2008.

20 Thangarajah H, Vial IN, Grogan RH, Yao D, Shi Y, Januszyk M, Galiano RD, Chang EI, Galvez MG, Glotzbach JP, Wong VW, Brownlee $M$ and Gurtner GC: HIF-1alpha dysfunction in diabetes. Cell Cycle 9: 75-79, 2010. 
21 Lee SH, Wolf PL, Escudero R, Deutsch R, Jamieson SW and Thistlethwaite PA: Early expression of angiogenesis factors in acute myocardial ischemia and infarction. $\mathrm{N}$ Engl $\mathrm{J}$ Med 342: 626-633, 2000.

22 Dimmeler S: Regulation of bone marrow-derived vascular progenitor cell mobilization and maintenance. Arterioscler Thromb Vasc Biol 30: 1088-1093, 2010.

23 Faeh D, Gutzwiller F and Bopp M; Swiss National Cohort Study Group: Lower mortality from coronary heart disease and stroke at higher altitudes in Switzerland. Circulation 120: 495-501, 2009.

24 Carmeliet P: Angiogenesis in life, disease and medicine. Nature 438: 932-936, 2005.

25 Folkman J: Tumor angiogenesis: therapeutic implications. N Engl J Med 285: 1182-1186, 1971.

26 Vaupel P, Mayer A and Höckel M: Tumor hypoxia and malignant progression. Methods Enzymol 381: 335-354, 2004.

27 Semenza GL: Defining the role of hypoxia-inducible factor 1 in cancer biology and therapeutics. Oncogene 29: 625-634, 2010.

28 Liao D and Johnson RS: Hypoxia: a key regulator of angiogenesis in cancer.Cancer Metastasis Rev 26: 281-290, 2007.

29 Bindra RS, Crosby ME and Glazer PM: Regulation of DNA repair in hypoxic cancer cells. Cancer Metastasis Rev 26: 249$260,2007$.

30 Lukashev D, Ohta A and Sitkovsky M: Hypoxia-dependent antiinflammatory pathways in protection of cancerous tissues. Cancer Metastasis Rev 26: 273-279, 2007.

31 Kim JW, Gao P and Dang CV: Effects of hypoxia on tumor metabolism. Cancer Metastasis Rev 26: 291-298, 2007.

32 Chan DA and Giaccia AJ: Hypoxia, gene expression, and metastasis. Cancer Metastasis Rev 26: 333-339, 2007.

33 Moeller BJ, Richardson RA and Dewhirst MW: Hypoxia and radiotherapy: opportunities for improved outcomes in cancer treatment. Cancer Metastasis Rev 26: 241-248, 2007.

34 Raval RR, Lau KW, Tran MG, Sowter HM, Mandriota SJ, Li JL, Pugh CW, Maxwell PH, Harris AL and Ratcliffe PJ: Contrasting properties of hypoxia-inducible factor 1 (HIF-1) and HIF-2 in von Hippel-Lindau-associated renal cell carcinoma. Mol Cell Biol 25: 5675-5686, 2005.

35 Gustafsson MV, Zheng X, Pereira T, Gradin K, Jin S, Lundkvist J, Ruas JL, Poellinger L, Lendahl U and Bondesson M: Hypoxia requires notch signaling to maintain the undifferentiated cell state. Dev Cell 9: 617-628, 2005.

36 Dvorak HF:Vascular permeability factor/vascular endothelial growth factor: a critical cytokine in tumor angiogenesis and a potential target for diagnosis and therapy. J Clin Oncol 20: 43684380, 2002.

37 Raa A, Stansberg C, Steen VM, Bjerkvig R, Reed RK and Stuhr LE: Hyperoxia retards growth and induces apoptosis and loss of glands and blood vessels in DMBA-induced rat mammary tumors. BMC Cancer 7: 23, 2007.

38 Zhang H, Gao P, Fukuda R, Kumar G, Krishnamachary B, Zeller KI, Dang CV and Semenza GL: HIF-1 inhibits mitochondrial biogenesis and cellular respiration in VHL-deficient renal cell carcinoma by repression of C-MYC activity. Cancer Cell 11: 407-420, 2007.

39 Kim KK, Abelman S, Yano N, Ribeiro JR, Singh RK, Tipping $\mathrm{M}$ and Moore RG: Tetrathiomolybdate inhibits mitochondrial complex IV and mediates degradation of hypoxia-inducible factor-1 $\alpha$ in cancer cells. Sci Rep 5: 14296, 2015.
40 Imai T, Horiuchi A, Wang C, Oka K, Ohira S, Nikaido T and Konishi I: Hypoxia attenuates the expression of E-cadherin via up-regulation of SNAIL in ovarian carcinoma cells. Am J Pathol 163: 1437-1447, 2003.

41 Ai Z, Lu Y, Qiu S and Fan Z: Overcoming cisplatin resistance of ovarian cancer cells by targeting HIF-1-regulated cancer metabolism. Cancer Lett 373: 36-44, 2016.

42 Kaelin WG Jr: Treatment of kidney cancer: insights provided by the VHL tumor-suppressor protein. Cancer 115: 2262-2272, 2009.

43 Linehan WM, Srinivasan R and Schmidt LS: The genetic basis of kidney cancer: a metabolic disease. Nat Rev Urol 7: 277-285, 2010.

44 Sufan RI, Moriyama EH, Mariampillai A, Roche O, Evans AJ, Alajez NM, Vitkin IA, Yang VX, Liu FF, Wilson BC and Ohh M: Oxygen-independent degradation of HIF-alpha via bioengineered VHL tumour suppressor complex. EMBO Mol Med 1: 66-78, 2009.

45 Pettersen EO, Ebbesen P, Gieling RG, Williams KJ, Dubois L, Lambin P, Ward C, Meehan J, Kunkler IH, Langdon SP, Ree AH, Flatmark K, Lyng H, Calzada MJ, Peso LD, Landazuri MO, Görlach A, Flamm H, Kieninger J, Urban G, Weltin A, Singleton DC, Haider S, Buffa FM, Harris AL, Scozzafava A, Supuran CT, Moser I, Jobst G, Busk M, Toustrup K, Overgaard J, Alsner J, Pouyssegur J, Chiche J, Mazure N, Marchiq I, Parks S, Ahmed A, Ashcroft M, Pastorekova S, Cao Y, Rouschop KM, Wouters BG, Koritzinsky M, Mujcic H and Cojocari D: Targeting tumour hypoxia to prevent cancer metastasis. From biology, biosensing and technology to drug development: the METOXIA consortium. J Enzyme Inhib Med Chem 30: 689-721, 2015.

46 Melillo G: Targeting hypoxia cell signaling for cancer therapy. Cancer Metastasis Rev 26: 341-352, 2007.

47 Zhang H, Qian DZ, Tan YS, Lee K, Gao P, Ren YR, Rey S, Hammers H, Chang D, Pili R, Dang CV, Liu JO and Semenza GL: Digoxin and other cardiac glycosides inhibit HIF-1alpha synthesis and block tumor growth. Proc Natl Acad Sci USA 105: 19579-19586, 2008.

48 Gill AL and Bell CN: Hyperbaric oxygen: its uses, mechanisms of action and outcomes. QJM 97: 385-395, 2004.

49 Brizel DM, Lin S, Johnson JL, Brooks J, Dewhirst MW and Piantadosi CA: The mechanisms by which hyperbaric oxygen and carbogen improve tumour oxygenation. Br J Cancer 72: 1120-1124, 1995.

50 Chen YC, Chen SY, Ho PS, Lin CH, Cheng YY, Wang JK and Sytwu HK: Apoptosis of T-leukemia and B-myeloma cancer cells induced by hyperbaric oxygen increased phosphorylation of p38 MAPK. Leuk Res 31: 805-815, 2007.

51 Gore A, Muralidhar M, Espey MG, Degenhardt K and Mantell LL: Hyperoxia sensing: from molecular mechanisms to significance in disease. J Immunotoxicol 7: 239-254, 2010.

52 Moen I, Øyan AM, Kalland KH, Tronstad KJ, Akslen LA, Chekenya M, Sakariassen PØ, Reed RK and Stuhr LE: Hyperoxic treatment induces mesenchymal-to-epithelial transition in a rat adenocarcinoma model. PLoS One 4: e6381, 2009.

53 De Bock K, Mazzone M and Carmeliet P: Antiangiogenic therapy, hypoxia, and metastasis: risky liaisons, or not? Nat Rev Clin Oncol 8: 393-404, 2011.

54 Feldmeier JJ, Heimbach RD, Davolt DA, Brakora MJ, Sheffield PJ and Porter AT: Does hyperbaric oxygen have a cancercausing or- promoting effect? A review of the pertinent literature. Undersea Hyperb Med 21: 467-475, 1994. 
55 Al-Waili NS, Butler GJ, Beale J, Hamilton RW, Lee BY and Lucas P: Hyperbaric oxygen and malignancies: a potential role in radiotherapy, chemotherapy, tumor surgery and phototherapy. Med Sci Monit 11: RA279-289, 2005.

56 Mayer R, Hamilton-Farrell MR, van der Kleij AJ, Schmutz J, Granström G, Sicko Z, Melamed Y, Carl UM, Hartmann KA, Jansen EC, Ditri L and Sminia P: Hyperbaric oxygen and radiotherapy. Strahlenther Onkol 181: 113-123, 2005.

57 Bocci V: Ozone. A new medical drug. The Netherlands, Springer Ed, 2005.

58 Bocci V, Luzzi E, Corradeschi F, Paulesu L and Di Stefano A: Studies on biological effects of ozone: 3 . An attempt to define conditions for optimal induction of cytokines. Lymphokine Cytokine Res 12: 121-126, 1993.

59 Pryor WA, Squadrito GL and Friedman M: The cascade mechanism to explain ozone toxicity: the role of lipid ozonation products. Free Radic Biol Med 19: 935-941, 1995.

60 Wang G, Guo Q, Hossain M, Fazio V, ZeynalovE, Janigro D, Mayberg MR and Namura S: Bone marrow-derived cells are the major source of MMP-9 contributing to blood-brain barrier dysfunction and infarct formation after ischemic stroke in mice. Brain Res 1294: 183-192, 2009.

61 Liu B, Wang J, Li M, Yuan Q, Xue M, Xu F and Chen Y: Inhibition of ALDH2 by O-GlcNAcylation contributes to the hyperglycemic exacerbation of myocardial ischemia/reperfusion injury. Oncotarget, 2016. doi: 10.18632/oncotarget.14297.

62 Bocci V and Aldinucci C: Biochemical modifications induced in human blood by oxygenation-ozonation. J Biochem Mol Toxicol 20: 133-138, 2006.

63 Aprioku JS:Pharmacology of Free Radicals and the Impact of Reactive Oxygen Species on the Testis. J Reprod Infertil 14: 158-172, 2013.

64 LoboV, Patil A, Phatak A and Chandra N: Free radicals, antioxidants and functional foods: Impact on human health. Free radicals, antioxidants and functional foods: Impact on human health. Free radicals, antioxidants and functional foods: Impact on human health. Pharmacogn Rev 4: 118-126, 2010.

65 Sagai M and Bocci V: Mechanisms of Action Involved in Ozone Therapy: Is healing induced via a mild oxidative stress? Med Gas Res 1: 29, 2011.

66 Bocci V: Oxygen-Ozone Therapy: A Critical Evaluation. Springer Science Business Media. Dordrecht Ed, 2002.

67 Coppola A, Coppola L, Luongo C, Arciello A, Cacciapuoti F, Lama D, Luongo M, Ruggiero L, Pastore A and Gombos G: Ozonized autohemotransfusion does not affect arterial vasodilation in patients with peripheral arterial disease. Int J Angiol 16: 7-11, 2007.

68 Catalanotti P, Lucido M, Luongo M, Folgore A, Luongo C and Gorga F: Attività antibatterica dell'ozono. $32^{\circ}$ National Congress Italian Society of Microbiology Milano 26-29/09. 2004. Abstract book, p. 88 .

69 Kal A, Kal O, Akillioglu I, Celik E, Yilmaz M, Gonul S, Solmaz $\mathrm{M}$ and Onal $\mathrm{O}$ : The protective effect of prophylactic ozone administration against retinal ischemia-reperfusion injury. Cutan Ocul Toxicol 36: 39-47, 2016.

70 Fuccio C, Luongo C, Capodanno P, Giordano C, Scafuro MA, Siniscalco D, Lettieri B, Rossi F, Maione S and Berrino L: A single subcutaneous injection of ozone prevents allodynia and decreases the over-expression of pro-inflammatory caspases in the orbito-frontal cortex of neuropathic mice. Eur J Pharmacol 603: 42-49, 2009
71 Zanardi I, Borrelli E, Valacchi G, Travagli V and Bocci V: Ozone: A Multifaceted Molecule with Unexpected Therapeutic Activity. Curr Med Chem 23: 304-314, 2016.

72 León Fernández OS, Ajamieh HH, Berlanga J, Menéndez S, Viebahn-Hánsler R, Re L and Carmona AM: Ozone oxidative preconditioning is mediated by $\mathrm{A} 1$ adenosine receptors in a rat model of liver ischemia/reperfusion. Transpl Int 21: 39-48, 2008.

73 Coppola L, Verrazzo G, Luongo C and SammartinoA: Variazioni della viscosità ematica e dell'aggregazione piastrinica indotte dall'ozono medicale a diverse concentrazioni. Studio in vitro. Rend Atti Accad Sci Med Chir 147: 155-167, 1993.

74 Di Filippo C, Marfella R, Capodanno P, Ferraraccio F, Coppola L, Luongo M, Mascolo L, Luongo C, Capuano A, Rossi F and D'Amico M: Acute oxygen-ozoneadministration to ratsprotects the heart from ischemia reperfusioninfarct. Inflamm Res 57: 445-449, 2008.

75 Giunta R, Coppola A, Luongo C, Sammartino A, Guastafierro S, Grassia A, Giunta L, Mascolo L, Tirelli A and Coppola L: Ozonized autohaemotransfusion improves hemorheological parameters and oxygen delivery to tissues in patients with peripheral occlusive arterial disease. Ann Hematol 12: 745-748, 2001.

76 Bocci V: Oxygen-ozone therapy, a critical evaluation. Kluwer Academic Publisher, 2002.

77 Bocci V: Does ozone really "cure" cancer? Int J Cancer 123: 1222,2008

78 Schulz S, Häussler U, Mandic R, Heverhagen JT, Neubauer A, Dünne AA, Werner JA,Weihe E and Bette M: Treatment with ozone/oxygen-pneumoperitoneum results in complete remission of rabbit squamous cell carcinomas. Intl Cancer 122: 2360-2367, 2008.

79 Clavo B, Pérez JL, López L, Suárez G, Lloret M, Rodríguez V, Macías D, Santana M, Hernández MA, Martín-Oliva R and Robaina F: Ozone therapy for tumor oxygenation: a pilot study. Evid Based Complement Alternat Med 1: 93-98, 2004.

80 Sweet F, Kao MS, Lee SC, Hagar WL and Sweet WE: Ozone selectively inhibits growth of human cancer cells. Science 209: 931-933, 1980

81 Coppola L, Luongo C, Pastore A, Masciello C, Parascandola RR, Mastrolorenzo L, Grassia A, Coppola A, De Biase M, Lettieri B and Gombos G: Ozonized autohaemotransfusion could be a potential rapid-acting antidepressant medication in elderly patients. Int J Geriatr Psychiatry 25: 208-213, 2010.

82 Coppola L, Giunta R, Verrazzo G, Luongo C, Sammartino A, Vicario $\mathrm{C}$ and Giugliano $\mathrm{D}$ : Influence of ozone on haemoglobinoxigen affinity in type -2 diabetic patients with peripheral vascular disease: in vitro studies. Diabete Metab 21: 251-255, 1995

83 Gilkes DM and Semenza GL:Role of hypoxia-inducible factors in breast cancer metastasis. Future Oncol 9: 1623-1636, 2013.

84 Hatfield SM, Kjaergaard J, Lukashev D, Schreiber TH, Belikoff B, Abbott R, Sethumadhavan S, Philbrook P, Ko K, Cannici R, Thayer M, Rodig S, Kutok JL, Jackson EK, Karger B, Podack ER, Ohta A and Sitkovsky MV: Immunological mechanisms of the antitumor effects of supplemental oxygenation. Sci Transl Med 7: 277ra30, 2015.

85 Hui-Mei Wu, Zi-Feng Jiang, Pei-Shan Ding, Li-Jie Shao and Rong-Yu Liu: Hypoxia-induced autophagy mediates cisplatin resistance in lung cancer cells. Scientific Reports 55: 12291, 2015. 
86 Delgado-Roche L, Hernández-Matos Y, Medina EA, Morejón DÁ, González MR and Martínez-Sánchez G: Ozone-Oxidative Preconditioning Prevents Doxorubicin-induced Cardiotoxicity in Sprague-Dawley Rats. Sultan Qaboos University Med J 14: e342-348, 2014.

87 Bocci V, Zanardi I and Travagli V: Important details to be clarified about the effect of rectal ozone on the portal vein oxygenation. Br J Clin Pharmacol 72: 350-351, 2011.

88 Shah YM: The role of hypoxia in intestinal inflammation. Mol Cell Pediatr 3: 1, 2016.

89 Fuccio C, Luongo C, Capodanno P, Giordano C, Scafuro MA, Siniscalco D, Lettieri B, Rossi F, Maione S and Berrino L: A single subcutaneous injection of ozone prevents allodynia and decreases the over-expression of pro-inflammatory caspases in the orbito-frontal cortex of neuropathic mice. Eur J Pharmacol 603: 42-49, 2009 .
90 Clavo B, Santana-Rodriguez N, Llontop P, Gutierrez D, Ceballos D, Méndez C, Rovira G, Suarez G, Rey-Baltar D, GarciaCabrera L, Martínez-Sánchez G and Fiuza D: Ozone therapy in the management of persistent radiation-induced rectal bleeding in prostate cancer patients. Evid Based Complement Alternat Med 2015: 480369, 2015.

91 Kuroda K, Azuma K, Mori T, Kawamoto K, Murahata Y, Tsuka $\mathrm{T}$, Osaki $\mathrm{T}$, Ito $\mathrm{N}$, Imagawa $\mathrm{T}$, Itoh $\mathrm{F}$ and Okamoto $\mathrm{Y}$ : The safety and anti-tumor effects of ozonated water in vivo. Int J Mol Sci 16: 25108-2520, 2015. 